\title{
O humor irônico dos contratempos políticos na websérie Porta dos Fundos
}

\author{
Carla Montuori Fernandes ${ }^{1}$ \\ Patrícia Cristina de Lima ${ }^{2}$
}

\begin{abstract}
Resumo: Este artigo tem como objetivo investigar a relação entre humor e política com base na websérie brasileira do grupo humorístico Porta dos Fundos, analisando como seus conteúdos representam os eventos políticos e seus personagens no período de mandato da ex-presidente Dilma Rousseff (PT). O recorte para pesquisa se inicia com as manifestações sociais de junho de 2013 e se encerra no desdobramento da crise política, com o início da votação do impeachment na Câmara dos Deputados, em abril de 2016. Como metodologia, foi definida a análise de conteúdo de Laurence Bardin (2011), aplicada nos seis episódios selecionados do grupo cuja temática central era o cenário político.
\end{abstract}

Palavras-chave: política; humor; internet; Porta dos Fundos.

\begin{abstract}
This article aims to study the connection between comedy and politics of the Brazilian webseries of the Porta dos Fundos group, analyzing how its contents represented the political events and characters during the term of office of former President Dilma Rousseff (PT). The timeframe of this survey begins with the social protests of June 2013, and ends in the unfolding political crisis, with the beginning of the impeachment vote in the House of Representatives, in April 2016. For methodology, the Content Analysis of Laurence Bardin (2011) was chosen and applied to the six episodes of the group that had this political landscape as the main topic of the episodes.
\end{abstract}

Keywords: politics; comedy; internet; Porta dos Fundos.

\section{Introdução}

Este artigo tem como objetivo investigar a relação entre humor e política com base na websérie brasileira do grupo Porta dos Fundos, analisando como seus conteúdos representam os personagens políticos no período que deu origem à crise

\footnotetext{
${ }^{1}$ Doutora e Pós-Doutora em Ciências Sociais pela Pontificia Universidade Católica de São Paulo (PUC-SP). É docente do programa de Pós-Graduação em Comunicação e Cultura das Mídias da Universidade Paulista (UNIP). E-mail: carla_montuori@ig.com.br.

${ }^{2}$ Mestre em Comunicação pela Universidade Paulista (UNIP). Atualmente é docente do Centro Universitário Estácio de Ribeirão Preto.E-mail: patricia.ppcoc@gmail.com.
} 
política, iniciada com as manifestações sociais de junho de 2013 até a votação do impeachment da ex-presidente Dilma Rousseff (PT), na Câmara dos Deputados, em 17 de abril de 2016.

Há muito tempo, a política nutre criações humorísticas. Slavutzky (2014) considera o humor como um mecanismo de rebeldia usado para desafiar o autoritarismo e preservar a sanidade de quem o suporta. Citando exemplos como Josef Stalin e Adolf Hitler, o autor apresenta a perseguição ao humor político como ilustração ao seu poder de contraponto.

No Brasil, um exemplo dessa ação ocorreu com a dupla sertaneja humorística Alvarenga e Ranchinho, que cantava anedotas contra o governo de Getúlio Vargas (PASQUALIN, 2014). Durante o Estado Novo (1937-1945), Getúlio Vargas vislumbrou no humor a oportunidade de reforçar a imagem criada do seu governo. Alvarenga e Ranchinho conseguiram liberação do próprio Getúlio, após uma apresentação no Palácio do Catete. Pautados nos acontecimentos políticos, nada passava despercebido pela dupla sertaneja que satirizava o presidente em seu repertório (SIMÕES, 1995).

Assim, historicamente, a compreensão da piada está diretamente ligada ao conhecimento da origem do objeto satirizado. Para Stam (1992), ao analisar a obra de Bakhtin, que satirizava a burguesia de sua época assistindo às peças de teatro, percebe-se que o riso assumiu o papel de crítico, para ridicularizar o dogmatismo e o fanatismo. A crítica social permeada pelo riso passa por momentos políticos com total força.

Ao trazer o humor para a contemporaneidade, é possível encontrá-lo em praticamente todos os meios de comunicação. Seja nas tiras publicadas nos jornais, seja na televisão, com suas sitcoms, ou na Internet, nas mais variadas formas, o humor garantiu seu espaço e tem recebido tratamento de destaque. Após o advento da internet, é possível encontrar uma variedade de opções com os mais diferentes níveis de anedotas. A participação do público, que pode se apoderar da produção (JENKINS, 2009) ou produzi-la de forma original, deu à Internet o status de conhecimento (leia-se produção) coletivo. 
Nesse cenário, a ferramenta de maior alcance de produções audiovisuais pelo público da contemporaneidade parece ser o You Tube. Como resultado da popularização e da profissionalização, o You Tube se tornou um excelente suporte para produções independentes e fez emergir as chamadas webséries, programas seriados produzidos exclusivamente para a internet. A websérie brasileira de maior importância desde que o You Tube tornou-se acessível no Brasil é a produzida pelo grupo Porta dos Fundos, que as divulga pelo canal de mesmo nome. Este canal já produziu 78 episódios em que retrata a política atual.

Em várias situações, os integrantes fazem questão de informar que não há privilégios ou favorecimentos partidários. Todos estão suscetíveis a serem alvos das piadas. Em sua página no Facebook ${ }^{3}$, no dia 3 de abril de 2016, Antonio Tabet ilustrou a posição do grupo acerca dos movimentos políticos de março de 2016:

Cada um de nós no Porta tem uma posição política e cabe ao outro respeitála sem prejuízo da amizade que nos uniu. Isso é civilidade. E nós, como grupo, refletimos essa pluralidade no nosso trabalho quando existe mais de um lado da moeda, o que é saudável num país onde política é futebol, futebol é religião e religião é política.

O relato também se justificou pelo imenso número de comentários que classificavam o grupo de "petista". Em outro trecho do post, Tabet lembra que há vários vídeos contra o governo. A divisão política do grupo a que ele se refere é direcionada especialmente a Gregório Duvivier, ativista de esquerda que publica abertamente suas ideias via Facebook e na coluna "Gregório Duvivier: Crônicas", no jornal Folha de S.Paulo. O humorista recebe diariamente críticas às suas ideias e tem seus vídeos mal classificados no canal devido às piadas ácidas sobre o sistema judiciário e à forma como a direita conduz assuntos políticos no Brasil.

Numa analogia ao humor "que não poupa ninguém" e possui muitos alvos, o Porta dos Fundos posiciona-se criticamente em relação ao funcionamento do sistema político brasileiro.Diante das frequentes polêmicas e da alta repercussão dos vídeos, este artigo pretende analisar como o conteúdo veiculado nos episódios retrata os principais personagens do cenário político. Trata-se de uma forma de produção humorística que reflete a conjuntura política de maneira irônica e escrachada, sem

3 Disponível em: $<$ https://www.facebook.com/aptabet?fref=ts $>$. Acesso em: 5 abr. 2016. 
poupar críticas aos personagens representados? Acusados de partidarismo, os vídeos do Porta dos Fundos refletem alguma tendência política? Como metodologia para o estudo, foi selecionada a análise de conteúdo (BARDIN, 2011), que será mais bem aprofundada ao longo do artigo.

\section{Humor, política e internet}

O humor é libertador. Assim Freud (1927, p. 85) define o humor em seu trabalho O Humor. Ao assumir que o estado humano é determinante para as ações da vida, o autor atenta que o humor é rebelde, não resignado, "o princípio do prazer, que pode aqui afirmar-se contra a crueldade das circunstâncias reais”.

Entendendo o humor como um fator humano, Bergson (1987) afirma que a emoção é inimiga daquilo que ri, e rimos do que encontramos nos momentos de indiferença emocional, quando agimos pelo racional. Helitzer e Shatz (2014) argumentam que existe uma "fórmula" para a composição do humor: um alvo, o exagero na descrição das ações, um pouco de emoção que aproxima o ouvinte da história, a hostilidade apontando o ridículo do que está sendo descrito, o realismo da situação e a surpresa do resultado final.

Balogh, citada por Santos e Rossetti (2012), explica que o humor é crítico, por isso não é encontrado em algumas artes como as pinturas do século XVII, que tinham o propósito de enaltecer o objeto representado. É nesse sentido que Slavutzky aponta: "O humor é inevitavelmente político, pois está sempre na contramão. A piada é oposição, seja lá ao que for” (2014, p. 195).

Helitzer e Shatz (2014) apontam que o humor não é um mistério, possui fórmulas, métodos, assim como humor e comédia não são semelhantes. Humor é o todo, o conjunto de estado de espírito, uma ligação com o consciente (FREUD, 1927). Nos gêneros, é subdivido em sátira, sarcasmo (maldizer), ironia e paródia. A comédia nada mais é do que a interpretação destes formatos de humor. A sátira é uma imitação irreverente que busca valorizar os defeitos de quem está sendo satirizado. $\mathrm{O}$ sarcasmo tem como princípio a intenção do maldizer, do dizer algo para que todos tenham uma imagem ruim do que está sendo objeto do cômico. Já a ironia é uma ferramenta de ataque usada para dizer algo com outro sentido com o objetivo de mudar um comportamento ou uma ação. 
Por fim, a paródia é uma releitura cômica, que pode ter sentido negativo ou não. Magalhães (2008) cita ainda o humor negro, processo cujas piadas não se prendem ao "politicamente correto". No âmbito do humor político, a internet encontrou um recanto produtivo e acolhedor. O pioneiro em produzir humor exclusivamente para a Internet é o Humortadela. Iniciado em dezembro de 1995 por Sérgio Batista, era um compilado de piadas, charges e vídeos.

A partir do ano 2000, os blogs tornam-se populares, representando uma espécie de diários on-line, nos quais era possível postar textos e imagens. Outro fenômeno determinante para o humor na Internet foram as redes sociais. A chegada do You Tube em 2005 abriu portas para a produção coletiva do humor. Plataforma de suporte de vídeos do Google, o You Tube é aberto a qualquer usuário que queira divulgar seu vídeo para diversão ou trabalho, apresentando, inclusive, opções de divulgação profissional. Na web, os grupos usam o humor escrachado para retratar assuntos relevantes do cotidiano dos internautas. Por exemplo, em 2011, o canal Parafernalha criou esquetes exclusivas para o You Tube, um formato que em 2012 foi aperfeiçoado pelo Porta dos Fundos, objeto deste artigo.

O Porta dos Fundos foi criado por Antonio Pedro Tabet, Fábio Porchat, Gregório Duvivier, Ian SBF e João Vicente de Castro, produzindo humor para a web através de esquetes com temas variados e aproximadamente três minutos de duração. A temática das histórias é sempre ligada ao cotidiano ou a fatores históricos que, por algum motivo, voltam a ser assunto nos dias atuais.

\section{A representação da política na websérie do grupo Porta dos} Fundos: uma análise de conteúdo

A tarefa de descrever como determinados grupos são representados é fundamentada por Stuart Hall (2014), em um entrelaçamento com o imaginário social. Definida por Hall como parte fundamental do processo por meio do qual os sentidos são produzidos e trocados por membros de uma cultura, a representação envolve o uso da linguagem, de signos e de imagens que respondem por algo ou o simbolizam. Adotando uma abordagem construcionista, Hall argumenta que a produção de sentido ocorre no interior da linguagem por meio dos "signos, 
organizados em linguagens de diferentes tipos, para nos comunicarmos significativamente com os outros" (HALL, 1997, p. 93).

Soares acrescenta que a representação de sentido por meio da linguagem é produzida de forma intensa pelos meios de comunicação, uma vez que os produtos culturais produzidos pela mídia geram imagens colhidas do mundo empírico para apresentá-las, "na categoria de 'representantes' de pessoas, situações e fatos" (2007, p. 51).

Como metodologia para identificar como a websérie do Porta dos Fundos representa os personagens políticos, recorreu-se à análise do conteúdo, na qual temática e procedimentos são considerados num "conjunto de técnicas de análise das comunicações" (BARDIN, 2011, p. 44). Para que esta significação fosse possível, as três etapas de análise de Bardin foram cumpridas: pré-análise, exploração do material e interpretação dos resultados.

Na fase de pré-análise, foram selecionados seis episódios da websérie. Além da temática política, os episódios também foram escolhidos considerando o número de visualizações - mínimo de dois milhões - e as características de representação dos personagens no momento da produção. Todos têm por tema momentos do mandato da presidente Dilma, iniciando-se com as manifestações sociais de junho de 2013 até o desdobramento da crise política, com o início da votação do impeachment, em 17 de abril de 2016. Em ordem cronológica, os episódios selecionados foram:

- "Reunião de emergência”, veiculado em 26 de junho de 2013, com 8.614.816 visualizações. $O$ episódio traz a representação cômica de uma reunião entre a presidente e alguns políticos preocupados com as manifestações populares de junho de 2013.

- "Financiamento", veiculado em 27 de setembro de 2014, com 3.944.567 visualizações. O programa critica de forma humorística a relação entre candidatos e grandes empresas do setor privado, em alusão ao financiamento das campanhas políticas.

- “Alianças", publicado em 9 de novembro de 2014, com 3.041.233 visualizações. Produzido logo após a reeleição de Dilma, o programa aborda a aliança entre o governo e o Partido do Movimento Democrático Brasileiro (PMDB), em 
referência ao país comandado por terceiros, pois a presidente encontrava-se enfraquecida.

- "Reunião de emergência 2", veiculado em 21 de março de 2016, com 3.862.707 visualizações. O vídeo foi produzido logo após as manifestações de 13 de março de 2016 e satirizou a situação da presidente Dilma, a ascensão de Temer como figura de articulação e ações da Polícia Federal junto aos investigados em variados tipos de processos criminais.

- "Delação", veiculado em 2 de abril de 2016, até 9 de maio contabilizava 7.045.040 visualizações e 573.729 dislikes, ou seja, o recorde de negativações de um vídeo do grupo e uma das maiores avaliações negativas da história do YouTube. Protagonizado pelo militante de esquerda Gregório Duvivier e por Fábio Porchat, o vídeo satiriza a Operação Lava Jato e a seletividade da mídia em divulgar informações dos envolvidos nas investigações.

- "Reunião de emergência 3, a delação 2", publicado em 11 de abril de 2016, como reposta aos comentários negativos e às acusações sofridas pelo grupo devido ao vídeo Delação. A sátira gira em torno dos comentários, memes e vídeos produzidos como forma de "protesto". A perda de seguidores e os questionamentos acerca das piadas religiosas também fizeram parte do conteúdo. Até 9 de maio de 2016, "Reunião de emergência 3" havia atingido 4.935.667 visualizações.

Como indicadores para análise, considerou-se uma série de práticas que, ao se incorporar à cultura política brasileira, ainda funcionam como objeto de negociação e trânsito no campo político. Uma breve concepção teórica acerca de tais práticas auxiliará na formulação dos indicadores que estão comumente associados à conjuntura atual.

Como ponto de partida, destacam-se as coalizões partidárias. No Brasil, as coalizões costumam se consolidar nos períodos eleitorais, tendo por base apenas a figura do personagem político, desobrigada da negociação de uma proposta de governo que seja comum aos partidos da aliança eleitoral (TEIXEIRA, 2004). Ao formar essa coalizão, ou seja, uma coligação composta por diversas alianças partidárias, o presidente consegue a lealdade de sua base de sustentação no Congresso. 
Ao refletir sobre as imensas competitividade e diversidade do sistema político brasileiro, Santos (1999, p. 117) aponta que "governar com o Congresso é o mesmo que dizer 'governar com coalizões', cuja solda obtém-se pela mistura parcial de identidades de interesses e intermináveis esforços de persuasão". O funcionamento da coalizão está intrinsecamente ligado a barganhas e chantagens políticas, praticadas por meio da distribuição de cargos públicos, concessão de benefícios, pagamentos de propinas, entre outras ilicitudes.

Como exemplo das chantagens políticas, vale relembrar que a atribulada campanha eleitoral para a reeleição de Dilma em 2014 foi marcada pelo início da Operação Lava Jato, deflagrada em março de 2014, e pela ampliação de denúncias de corrupção envolvendo partidos e políticos da base aliada, especialmente o PT e o PMDB. Nesse contexto, o fisiologismo tornou-se a arma dos membros do Congresso Nacional contra o Planalto,liderados pelo deputado federal Eduardo Cunha (PMDB) e pelo senador Renan Calheiros (PMDB), presidentes da Câmara dos Deputados e do Senado, respectivamente.

O estopim para a crise de relacionamento entre a presidente Dilma e as casas legislativas aconteceu em maio de 2013, com a votação da Medida Provisória n. 595/12, a chamada MP dos Portos. Nesta MP, o governo buscava meios de modernização das vias marítimas de exportação/importação. A lei, posteriormente Lei n. 12.815/2013, facilita os processos de exploração e concessão dos portos brasileiros. Eduardo Cunha, líder do partido na Câmara, articulou para que o projeto fosse modificado e, assim, aprovado. Porém, ao ir para a sanção presidencial, foi novamente alterado. Para parte da base aliada e para a oposição, Dilma não cumpriu acordos realizados anteriormente entre governo, empresas e parlamentares, ao vetar 13 pontos cruciais, entre eles, a renovação antecipada de contratos de concessão.

Paralelamente às discordâncias no cenário federal, em junho de 2013, uma sequência de protestos ocorreu em várias capitais brasileiras. Motivadas pelo aumento das tarifas de ônibus, as manifestações se iniciaram pela internet. Em São Paulo, o anúncio do governador Geraldo Alckmin (PSDB) e do prefeito da capital na época, Fernando Haddad (PT), sobre o aumento das tarifas de trens e metrôs de R\$ 3,00 para $R$ \$ 3,20 fez eclodir uma série de manifestações na cidade e em outros 
locais. Em Brasília, no dia 20 de junho, mais de 100 mil pessoas tomaram a Esplanada dos Ministérios e gritos de "O gigante acordou" e "Não é por 20 centavos, é por direitos" ganharam força, e essas expressões também tomaram a Internet.

Em 2013, a base do governo já havia se organizado para as eleições que deveriam ocorrer em outubro de 2014. Dilma foi escolhida a representante do bloco para a reeleição ao cargo de presidente. A coligação, nomeada "Com a força do povo", contava com o PT, na figura de Dilma, e o PMDB, com o vice Michel Temer, seguidos dos partidos PSD, PP, PR, PROS, PDT, PC do B e PRB.

As eleições, que se tornaram as mais disputadas do período posterior à redemocratização, terminaram com a reeleição de Dilma por 51,64\% dos votos válidos, apenas $3,28 \%$ à frente do concorrente, Aécio Neves (PSDB). Ao final da divulgação dos resultados, Aécio chegou a reconhecer a derrota, mas iniciou imediatamente uma campanha de oposição à presidente eleita.

Em dezembro de 2014, com um déficit de $\mathrm{R} \$ 80$ bilhões, o governo anunciou um pacote de medidas para equilibrar as contas. Durante a campanha, Dilma chegou a afirmar que o país não passava por problemas econômicos. O primeiro ano do segundo mandato presidencial de Dilma, em 2015, contou com a eleição de Eduardo Cunha para a presidência da Câmara de Deputados. Isso abalou a relação entre o PMDB e o PT, já que o oponente para o cargo era o deputado Arlindo Chinaglia (PT).

Em 2 de dezembro de 2015, após a bancada do PT anunciar que votaria a favor do pedido de cassação de Cunha, por ter mentido no Comitê de Ética, o então presidente da Câmara aceitou o pedido de impeachment protocolado pelos juristas Miguel Reale Jr., Hélio Bicudo e Janaína Paschoal, baseado nas chamadas "pedaladas fiscais".

No dia 15 de março de 2015, o país presenciou a maior manifestação popular desde as Diretas Já, em 1984. Insatisfeitas com as medidas econômicas e contaminadas pelo discurso de impeachment, cerca de dois milhões de pessoas foram às ruas em diversas regiões do país. Ataques ao PT e apoio à Lava-Jato foram temas das manifestações nas ruas e na internet. (cf. PENTEADO e GUERBALI, 2016).

A situação política do governo se deteriorou com o vazamento da delação de Delcídio do Amaral na Lava-Jato, no dia 3 de março de 2016. Nas informações, o ex- 
senador acusa Dilma e Lula de intervirem no Supremo Tribunal de Justiça (STJ) e no Supremo Tribunal Federal (STF) para barrar as ações da Polícia Federal. No dia seguinte ao vazamento, o ex-presidente Lula é levado para depor, via condução coercitiva pela Polícia Federal, ao aeroporto de Congonhas, em São Paulo, onde Moro o aguardava. Concomitantemente, um pedido de prisão preventiva de Lula foi expedido pelo Ministério Público de São Paulo (MP-SP), em um processo que investiga a identidade do dono de um apartamento tríplex, no Guarujá.

No dia 16 de março, Dilma nomeou o ex-presidente Lula como ministro chefe da Casa Civil. Diante da suposta manobra política, o juiz Sérgio Moro tornou públicas as gravações telefônicas de conversas entre Dilma e Lula, em que o ex-presidente atacava o STF, chamando-o de "acovardado", criticando os presidentes da Câmara e do Senado, dizendo ainda que tinha medo da "república de Curitiba", referência à sede da Polícia Federal.

Além da questão das gravações, uma série de pedidos para o impedimento da nomeação de Lula começou a surgir nas varas estaduais e federais. Lula foi definitivamente impedido de assumir após decisão do ministro Gilmar Mendes, do STF. O episódio da nomeação de Lula enfraqueceu ainda mais Dilma diante dos adversários. No dia 29 de março, numa reunião que durou menos de dez minutos, o PMDB optou por romper com o governo e tornar-se oposição.

Após a breve retomada da conjuntura política, percebe-se a presença marcante do embate entre os personagens políticos e as rupturas partidárias como indicadores do estopim que ocasionaram contratempos políticos. $\mathrm{Na}$ fase de análise e interpretação dos resultados, as webséries foram analisadas com o intuito de identificar a ocorrência de matérias que comportavam os indicativos estabelecidos na fase anterior.

\section{Análise e interpretação dos resultados}

Os personagens de cada episódio são escolhidos levando em consideração o cenário político do momento da produção. No entanto, alguns se repetem de maneira sistemática. É o caso de Dilma e Lula, além de citações ao PMDB. Dilma e Lula são citados em cinco dos seis vídeos. 
É interessante observar como o processo de deterioração da imagem da expresidente Dilma cresce de acordo com a ordem cronológica dos vídeos. Em Reunião de emergência, Dilma aparece como representante central, colocada na ponta da mesa, numa simbologia clara de liderança. Suas falas são fortes e diretas, determinando ações de maneira objetiva (Figura 1).

\begin{tabular}{|l|c|c|}
\hline Tempo & Á́deo & Áudio \\
\hline o'03 & Burburinhos. \\
\hline 1'26 & $\begin{array}{c}\text { Mulher: É só um } \\
\text { corte de 2o por } \\
\text { cento! }\end{array}$ \\
\hline 1'43 & $\begin{array}{c}\text { Mulher: Gente, é só } \\
\text { o tempo de o povo } \\
\text { dispersar. Em um } \\
\text { mês tudo volta a ser } \\
\text { como era antes. Vai } \\
\text { voltar campeonato } \\
\text { Big Brother... }\end{array}$ \\
\hline
\end{tabular}

Figura 1: Representação postural de Dilma no episódio Reunião de emergência. Fonte: Print da websérie Porta dos Fundos 4

A presidente, mesmo pressionada por outros integrantes da mesa, ainda mantém a liderança e adota um tom conciliador durante a discussão. Isso retrata o

4 Disponível em: <www.youtube.com/watch?v=C9oxZOmsQ>. Acesso em: 25 abr. 2017. 
momento que Dilma vivia em 2013, após os desajustes com o PMDB e as decisões que contrariavam os acordos preestabelecidos com a base aliada. No vídeo, a presidente também se apresenta preocupada com as manifestações de junho de 2013. Essa postura focaliza a queda da popularidade do governo naquele momento, de $65 \%$ como bom/ótimo em março para 30\% no dia 28 de junho (DATAFOLHA, 2013).

A sátira dessa representação de Dilma se dá pela valorização da postura masculinizada e pelo tom forte diante da situação. Petry (2013) cita que as representações gráficas de humor da presidente sempre se dão nesse processo, com uma imagem de que uma mulher feminina é incapaz de governar. O processo de transformação da imagem de ex-militante em elegante senhora capaz de gerir um país é desmontada pelas fortes expressões faciais e corporais (Figura 2).

\begin{tabular}{|l|c|c|}
\hline Tempo & Vídeo & \multicolumn{1}{c|}{ Áudio } \\
\hline o'46 a & at9 &
\end{tabular}




\begin{tabular}{|c|c|c|}
\hline $1 ' 48$ & $\begin{array}{c}\text { Mulher: Lá na frente } \\
\text { você vai poder fazer } \\
\text { o que você quiser, } \\
\text { meu querido. }\end{array}$ \\
\hline
\end{tabular}

Figura 2: Expressões faciais de Dilma no episódio Reunião de emergência. Fonte: Print da websérie Porta dos Fundos 5

Já em Alianças, a presidente é representada como uma pessoa desinformada e submissa às decisões das coligações. Todas as decisões são tomadas pelos assessores e pelo PMDB. Ao final do vídeo, Dilma aparece limpando o chão e questionando a rigidez dos processos da casa (Figura 3).

\begin{tabular}{|l|c|c|c|}
\hline Tempo & Vídeo & $\begin{array}{c}\text { Áudio } \\
\text { Mulher: Tá. Tá. E } \\
\text { quem são essas } \\
\text { pessoas aê? }\end{array}$ \\
\hline o'10 & & $\begin{array}{c}\text { Homem 1: Essa é a } \\
\text { sua nova bancada de } \\
\text { aliados. }\end{array}$ \\
\hline
\end{tabular}

${ }_{5}$ Disponível em: <www.youtube.com/watch?v=C90xZOmsQ>. Acesso em: 25 abr. 2017. 


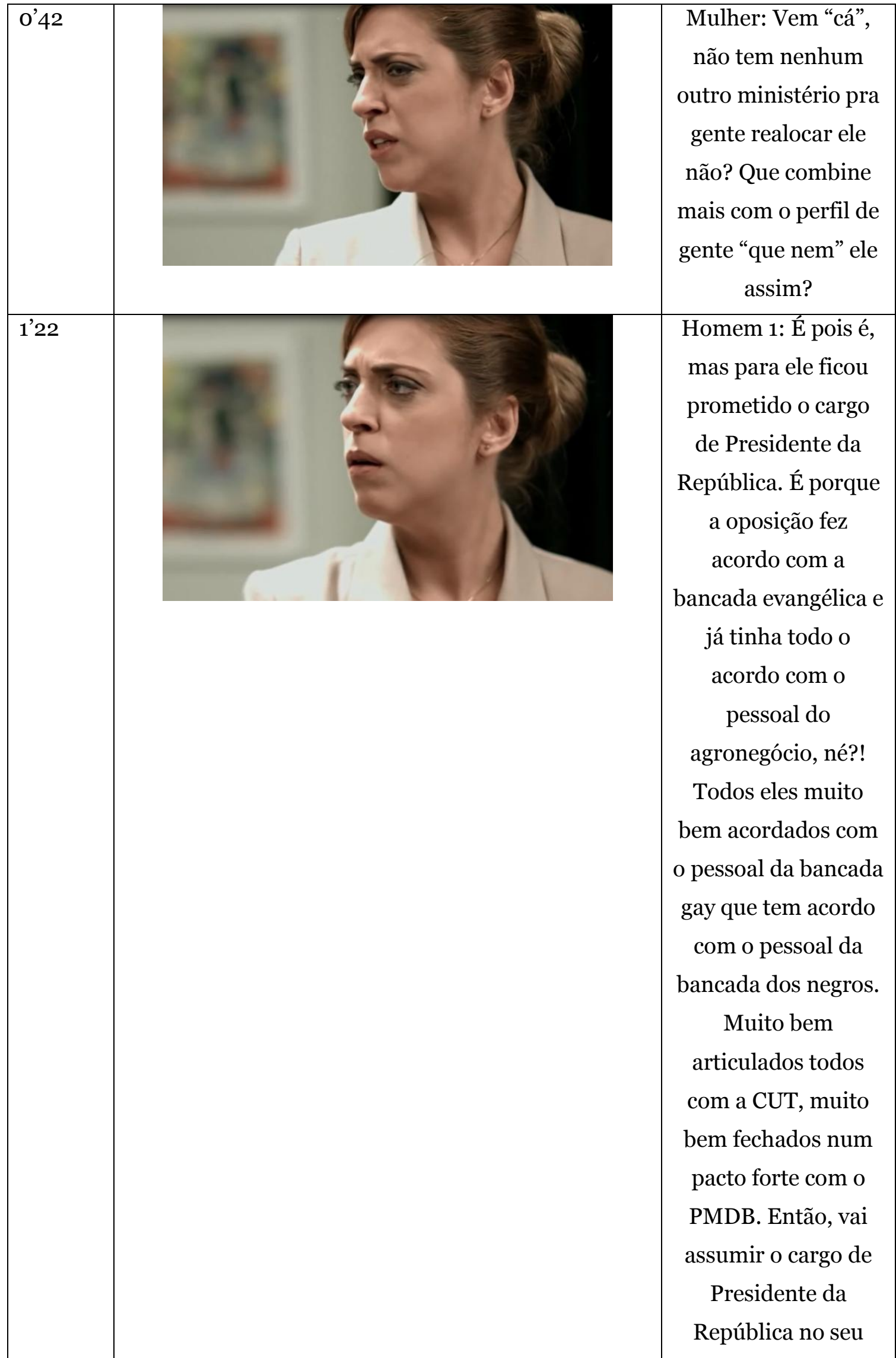




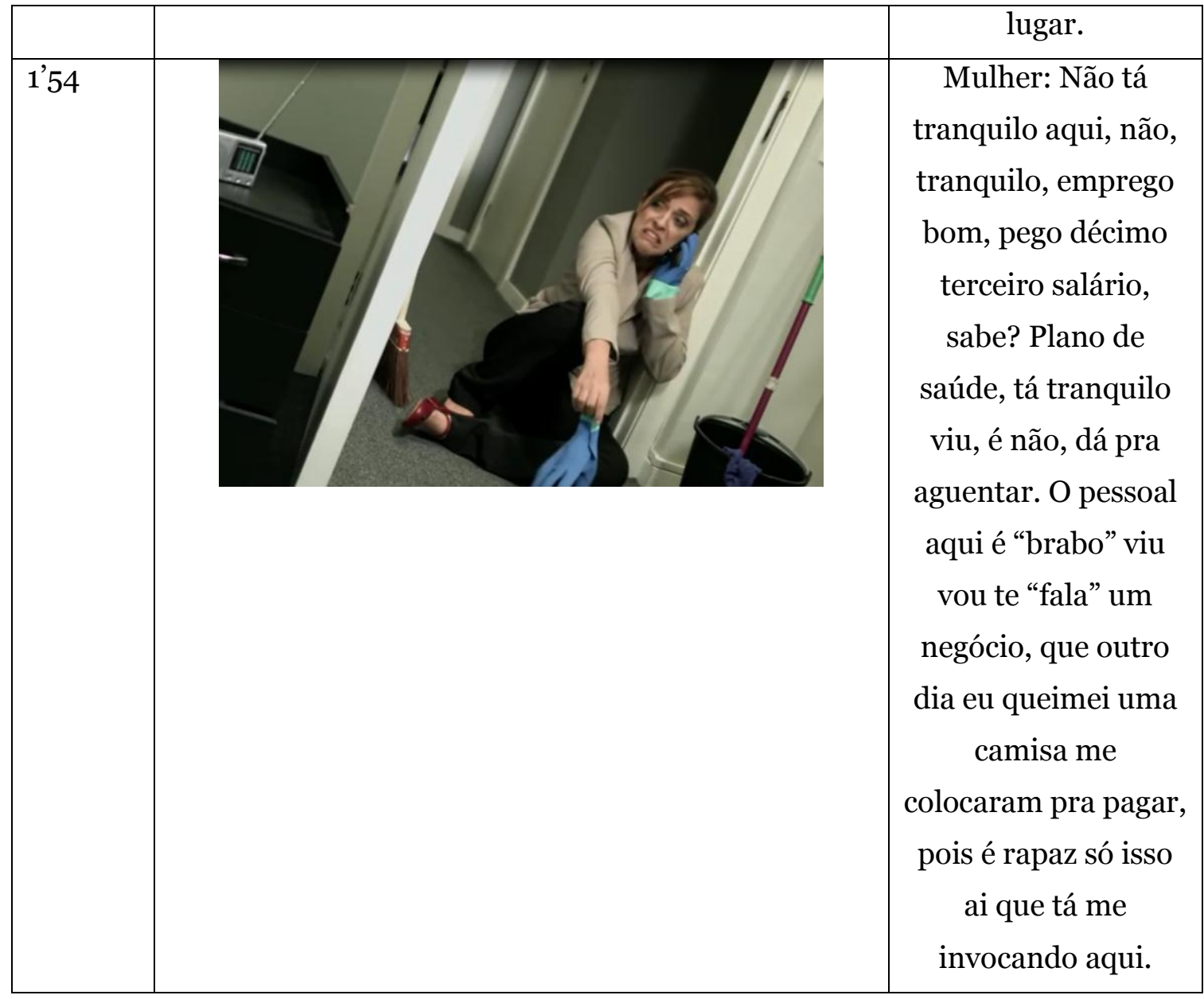

Figura 3: Representação de Dilma no episódio Alianças. Fonte: Print da websérie Porta dos Fundos ${ }^{6}$

Lançado dez dias após a definição do segundo turno eleitoral, esse episódio configura uma representação clara do cenário daquele momento. Trata-se de uma crítica à necessidade da criação de coligações para manter a base no Legislativo.O tom irônico se efetiva diante de uma situação em que Dilma deveria comandar a reunião com os coligados. A narrativa a representa como distante e desinformada, transmitindo a sensação de que todos no ambiente estão mais preparados e engajados do que a presidente eleita.

Em Reunião de emergência 2 e em Delação, Dilma já se apresenta como "fora do jogo”. No vídeo, Temer aparece como grande articulador, enquanto a presidente está acuada embaixo da mesa, numa clara referência ao processo de impeachment aceito por Eduardo Cunha e que já tramitava no Congresso. Além disso, havia a

${ }^{6}$ Disponível em: < $\underline{w w w . y o u t u b e . c o m / w a t c h ? v=Z ~ w o A W U c w S 4 ~>~ . ~ A c e s s o ~ e m: ~} 25$ abr. 2017. 
pressão popular causada pela sequência de manifestações no início de 2016 (Figura 4).

\begin{tabular}{|c|c|c|}
\hline Tempo & Vídeo & Áudio \\
\hline 1'21 & & $\begin{array}{l}\text { Homem 1: Tá aqui } \\
\text { embaixo, em } \\
\text { posição fetal, com } \\
\text { punho na boca. } \\
\text { Está chorando e } \\
\text { babando há duas } \\
\text { semanas desde que } \\
\text { saíram essas } \\
\text { ligações aê. Eu } \\
\text { estou interino no } \\
\text { lugar dela. }\end{array}$ \\
\hline
\end{tabular}

Figura 4: Representação de Dilma no episódio Reunião de emergência 2.

Fonte: Print da websérie Porta dos Fundos7

As ligações citadas no momento em que Dilma é representada no vídeo referem-se às gravações vazadas pela Polícia Federal, no dia 16 de março de 2016, acerca do acordo para tornar Lula ministro. A questão abalou claramente a presidente, que, nos dias seguintes, realizou discursos inflamados contra a ação.

Lula também é citado em quatro dos seis episódios selecionados. Em todas as ocasiões, o ex-presidente é apresentado como alguém temível, intocável e que lidera as decisões políticas. No episódio Reunião de emergência, Lula é citado de maneira direta, ao final do vídeo, quando um dos componentes da reunião quer saber quem contará ao ex-presidente sobre o que foi acordado na sala.

No episódio Reunião de emergência 2, Lula é mencionado como um líder com quem nenhum dos presentes quer lidar. Ao concluírem que o personagem "Linguiceiro de Diadema" assumirá o Ministério da Justiça, um dos presentes questiona se assim o Linguiceiro terá de lidar diretamente com o ex-presidente. O Linguiceiro, que está amordaçado e em uma camisa de força, desespera-se e grita continuamente (Figura 5).

7 Disponível em: <www.youtube.com/watch?v=hXuv3c1Rzo > . Acesso em: 25 abr. 2017. 


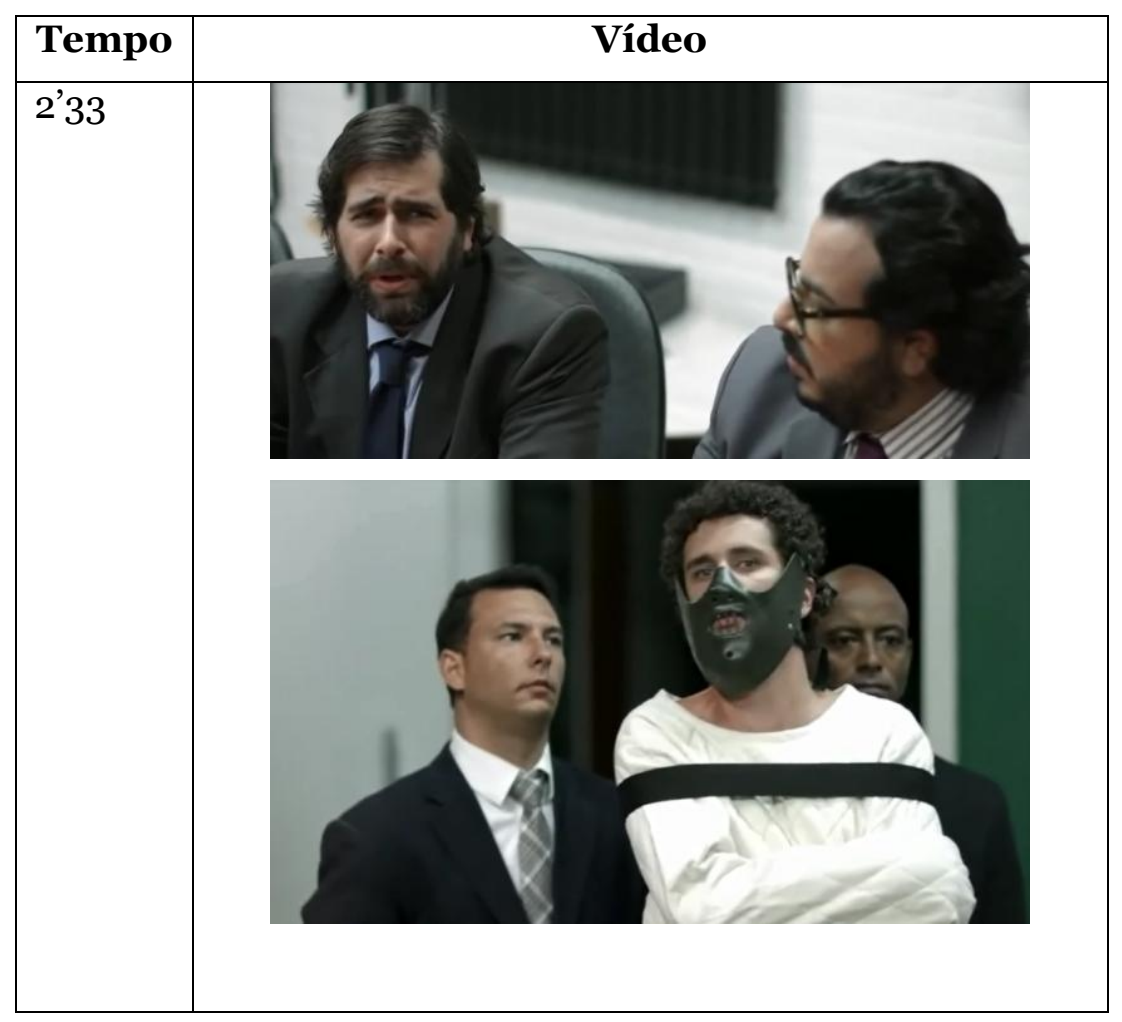

Figura 5: Representação de Lula no vídeo Reunião de Emergência 2. Fonte: Print da websérie Porta dos Fundos ${ }^{8}$

A mesma imagem de líder temido é reforçada no vídeo Delação, em que o personagem de Gregório Duvivier, um policial federal, se empolga com a notícia de que conseguiu uma forma de emitir um mandado de prisão, em uma clara alusão à sequência de citações do nome do ex-presidente nas ações da Lava Jato. Por fim, em Reunião de emergência 3, a delação 2, Lula é citado como um líder carismático e que cativa multidões. Citado como inatingível no trecho em que João Vicente diz não se preocupar com as regras, e que ligará diretamente para contar a situação, Lula é mostrado como um grande articulador político. No tempo de 1'02 minutos de vídeo, Gregório utiliza a frase "Lula é um ladrão que roubou meu coração!", para ilustrar a relação ambígua da imagem do ex-presidente com apoiadores e críticos (Figura 6).

${ }^{8}$ Disponível em: <www.youtube.com/watch?v=hXuv3c1Rz o > . Acesso em: 25 abr. 2017. 


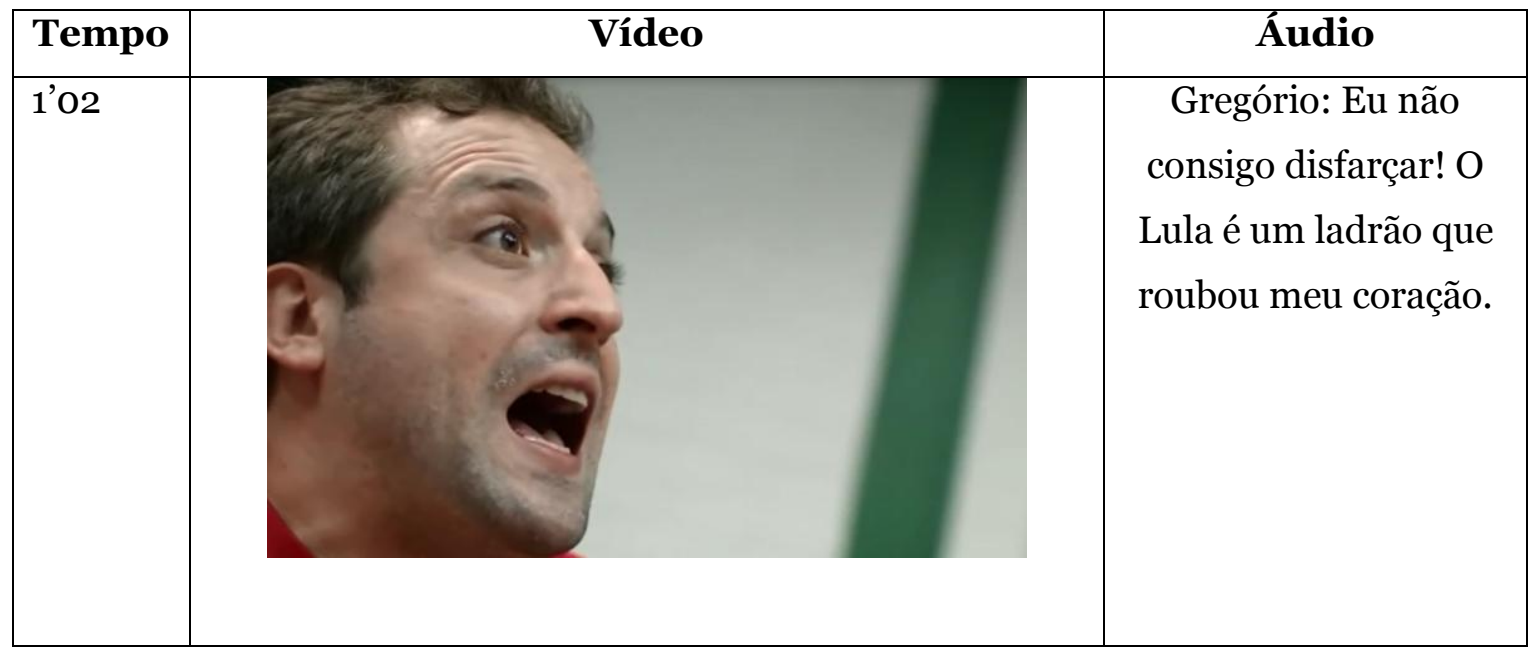

Figura 6: Representação de Lula no vídeo Reunião de Emergência 3, Delação 2. Fonte: Print da websérie Porta dos Fundos9

A representação de Lula pelo Porta dos Fundos mostra o ex-presidente como uma figura importante dos bastidores políticos, já que nenhum personagem é alocado para interpretá-lo. A sátira construída em torno do ex-presidente valoriza a postura de segundo plano, assumida no período do governo de Dilma. Além disso, a ironia se constitui pela força da imagem de liderança de Lula, que, apesar de inúmeras denúncias e supostos envolvimentos em casos de corrupção, mantém respeito político e forte apoio popular.

O PMDB é representado diretamente em três episódios: Reunião de emergência, Reunião de emergência 2 e Delação. No vídeo Reunião de emergência, um dos personagens fala com forte sotaque e afirma que não irá realizar obras para acalmar o âmbito popular. Ao dizer que "não jogou o Maranhão na merda", o personagem faz uma clara referência a José Sarney (PMDB), presidente do Senado até fevereiro de 2013, e pertencente a uma tradicional família política do estado do Maranhão, uma das mais ricas do país. O estado do então senador apresenta um dos maiores índices de desigualdade social, além da pior infraestrutura educacional do Brasilio.

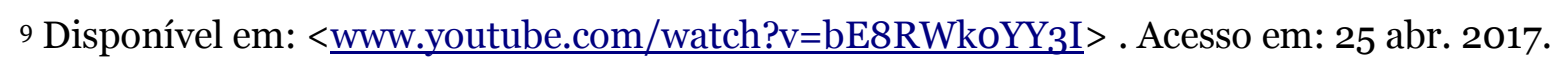
${ }^{10}$ Os dados completos acerca da situação social do país podem ser verificados através do "Mapa da exclusão social no Brasil", livro de José de Jesus Sousa Lemos, com terceira edição atualizada publicada em 2012. $\mathrm{O}$ acesso é gratuito através do endereço: 
Já Michel Temer (PMDB) é mostrado em Reunião de emergência 2 como grande articulador. No vídeo, a postura dos componentes da mesa ao lidar com Michel é diferente da postura quando Dilma é figura central. Reforçando a questão da misoginia, há um claro respeito e um tom mais ameno ao apresentar a contradição das decisões que um homem - no caso Michel Temer - toma do que quando é uma mulher a centralizadora. Com o impeachment de Dilma dado como certo, os olhares passaram a se voltar para Temer, que posteriormente assumiria a presidência. No caso do vídeo, Temer já toma as decisões e encaminha os processos (Figura 7).

\begin{tabular}{|l|c|c|c|}
\hline Tempo & Vídeo & Áudio \\
\hline o'oo & & $\begin{array}{c}\text { Homem 1: Senhores } \\
\text { ministros, a situação } \\
\text { piorou. Eu convoquei } \\
\text { essa reunião de } \\
\text { emergência. } \\
\text { Infelizmente, um de } \\
\text { vocês vai ter que ser } \\
\text { demitido. }\end{array}$ \\
\hline
\end{tabular}

Figura 7: Representação de Michel Temer no vídeo Reunião de Emergência 2 Fonte: Print da websérie Porta dos Fundos ${ }^{11}$

A articulação do PMDB junto a outros partidos também é citada no vídeo Delação. Na ocasião, o deputado que realiza a delação diz que a reunião em Paris foi um encontro de aliados entre o partido e o PSDB. No vídeo Alianças, duas figuras representativas do partido são citadas. A primeira é o ex-presidente Fernando Henrique Cardoso. No vídeo, Fernandinho, como é chamado no episódio, diz que será denunciado no programa Fantástico pelo esquema de gerenciamento de águas de São Paulo. O uso de FHC não foi em vão. Nas duas campanhas eleitorais para presidência em que saiu vitorioso (1994 e 1998), a promessa de transposição do rio São Francisco foi firmada.

$<$ http://www.bnb.gov.br/projwebren/Exec/livroPDF.aspx?cd livro=224>. Acesso em: 06 jan. 2017.

${ }^{11}$ Disponível em: $<$ www.youtube.com/watch?v=hXuv3c1Rz o $>$. Acesso em: 25 abr. 2017. 
Num segundo momento do episódio Alianças, o senador mineiro Aécio Neves é representado. No trecho em que o assessor explica o que "o querido senador" está fazendo ali, Dilma faz questão de dizer que o derrotou na eleição, mas é interrompida e toma conhecimento de que o oponente possui mais apoio e alianças, e, portanto, irá governar no seu lugar. O processo de representação de Aécio consiste basicamente em mostrá-lo como político que assumiu a oposição, mesmo após ter reconhecido a derrota nas urnas, e que desde então trabalhava diariamente para retirar a presidente eleita do poder.

Já no vídeo Delação, o PSDB é o grande satirizado. O delator apresenta uma sequência de políticos, que juntos receberam $\mathrm{R} \$ 25$ milhões da Vale e $\mathrm{R}$ \$ 35 milhões da Petrobras. No entanto, as denúncias são recusadas pelo agente da Polícia Federal, numa clara alusão ao grande número de denúncias que são engavetadas nos governos tucanos. Fernando Henrique também é citado em Delação. A questão colocada foi a suposta compra de votos para a emenda que permitia a reeleição do então Presidente da República, em 1997.

A política de coalizão é retratada com mais destaque no episódio Alianças. O vídeo Alianças ilustra um cenário complexo para a presidente Dilma. A sequência de manifestações contrárias ao governo e as articulações de Eduardo Cunha no chamado "blocão" fizeram com que Dilma tivesse que ceder muito para manter a base aliada (Figura 8).

\begin{tabular}{|l|c|c|}
\hline Tempo & Vídeo & \multicolumn{1}{c|}{ Áudio } \\
\hline 1'40 & & $\begin{array}{c}\text { Homem 1: a senhora } \\
\text { Presidente fez tanto } \\
\text { acordo, tanta aliança, } \\
\text { que a gente te perdeu } \\
\text { em algum momento, e } \\
\text { a senhora vai de } \\
\text { suplente do Renan } \\
\text { mesmo, que também é } \\
\text { PMDB. }\end{array}$ \\
\\
\hline
\end{tabular}

Figura 8: Política de coalização no episódio Alianças. Fonte: Print da websérie Porta dos Fundos12

${ }_{12}$ Disponível em: < $\underline{w w w . y o u t u b e . c o m / w a t c h ? v=m 92 w w s C x k 7 k}>$.Acesso em: 25 abr. 2017. 
O Porta dos Fundos ilustra a política de coalizão de forma satírica, valorizando as perversidades do processo e se aproximando do sarcasmo. Trata com humor também o fato de que, além de bom gestor, o presidente precisa ser eficaz negociador.

\section{Considerações finais}

O objetivo central deste estudo foi entender como personagens e eventos políticos foram representados nos episódios do grupo Porta dos Fundos e se existia algum favorecimento político-partidário. Como resultado, pode-se perceber que a raiz histórica do humor de satirizar quem detém o poder se manteve na websérie. Ao selecionar o recorte do governo Dilma, entre os anos de 2013 e 2016, nota-se que a presidente e seu padrinho político, Lula, foram os alvos centrais. No caso das amostras selecionadas, os aspectos se revezavam, mantendo sempre como foco as ações dessas autoridades e seus reflexos junto à população.

No entanto, os episódios analisados também mostram a habilidade de trazer antigos escândalos, ou mesmo de escancarar questões políticas que pertenciam apenas aos bastidores. Através de seus roteiros, o Porta dos Fundos desconstrói a imagem política e evidencia alguns fatos. Ao reafirmar que manterá seu estilo, independente da aprovação, o grupo reforça um discurso comum entre os humoristas contemporâneos: a piada precisa ser levada menos a sério, pois é o que está sendo satirizado que importa, não quem satiriza.

Por fim, é clara a dominação da ironia e do sarcasmo na representação dos personagens e eventos políticos por parte do Porta dos Fundos. A incredulidade na classe governista se revela em todos os roteiros analisados da amostra. Outro aspecto que caracteriza o humor do grupo é a sua habilidade de manter a sátira, mesmo tendo posturas pessoais divergentes.

\section{Referências}

BARDIN, Laurence. Análise de conteúdo. Lisboa: 70, 2011.

BERGSON, Henri. O riso. Rio de Janeiro: Zahar, 1983.

FREUD, Sigmund. O humor (1927). In: Edição Standart das ObrasCompletas de Sigmund Freud. v. 21, Rio de Janeiro: Imago, 1977, p.189-194. 
HELITZER, Mel ; SHATZ, Mark. Como escrever humor. Rio de Janeiro: Gryphus, 2014.

JENKINS, Henry. Cultura da convergência. São Paulo: Aleph, 2009.

MAGAlHÃES, Helena Maria G.. [...] e o negro amarelou: um estudo sobre o humor negro verbal brasileiro. Tese (Doutorado em Letras). Pontifícia Universidade Católica de Minas Gerais, 2008.

PASQUALIN, Vera da Cunha. Os desafios da produção midiática na década de 1940: o caso do artista-comunicador José Medina. Trabalho apresentado no $\mathbf{1 0}^{\mathbf{0}}$ Encontro Internacional de Música e Mídia. São Paulo, 2014.

PENTEADO, Cláudio; GUERBALI, João Guilherme. As manifestações do impeachment no Twitter: uma análise sobre as manifestações de 2015. Revista Ponto e Vírgula, n. 19 - p. 23 a 43- 2016.

PETRY, Michele Bete. O corpo nas expressões gráficas de humor: Dilma Rousseff e a política brasileira contemporânea. Curitiba: Editora CRV, 2013.

SANTOS, Wanderley Guilherme dos. Regresso. Máscaras institucionais do liberalismo oligárquico. Rio de Janeiro: Opera Nostra, 1999.

SANTOS, Roberto Elisio dos.; ROSSETTI, Regina. Humor e riso na cultura midiática: variações e permanências. São Paulo: Paulinas, 2012.

SIMÕES, Alex Caldas. 170 de caricatura no Brasil: Personagens, temas e fatos. Revista Linguagens, v. 15 - p. 1 a 19 - 2010.

SOARES, Murilo César. Representações, jornalismo e a esfera pública democrática. São Paulo: Cultura Acadêmica, 2007.

STAM, Robert. Bakhtin: da teoria literária à cultura de massa. São Paulo: Ática, 1992.

SLAVUTZKY, Abrão. Humor é coisa séria. Porto Alegre: Arquipélago Editorial, 2014. 